\title{
Preoperative Magnetic Resonance and Intraoperative Ultrasound Fusion Imaging for Real-Time Neuronavigation in Brain Tumor Surgery
}

\section{Präoperative MRI- und intraoperative Ultraschallfusion für die Echtzeit-Neuronavigation in der Neurochirurgie von Hirntumoren}

Authors

Affiliations

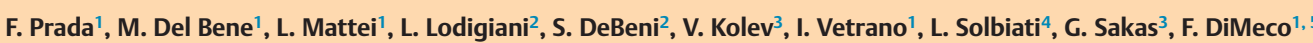

\author{
Neurosurgery, Fondazione IRCCS Istituto Neurologico C. Besta, Milano, Italy \\ Research and Development, Esaote S. p. a., Genova, Italy \\ Research and Development, MedCom, Darmstadt, Germany \\ Interventional Oncology, A. O. Circolo, Busto Arsizio, Italy \\ Department of Neurological Surgery, The Johns Hopkins Medical School, Baltimore, USA
}

Key words
brain
tumor
surgery
ultrasound
intraoperative

received 26.1.2014

accepted $\quad 3.8 .2014$

\section{Bibliography}

DOI http://dx.doi.org/

10.1055/s-0034-1385347

Published online: November 27, 2014

Ultraschall in Med 2015; 36: 174-186 @ Georg Thieme Verlag KG Stuttgart · New York . ISSN 0172-4614

\section{Correspondence \\ Dr. Francesco Prada}

Neurosurgery, Fondazione IRCCS Istituto Neurologico

C. Besta

via Celoria 11

20133 Milano

Italy

Tel.: ++ 39/02/23942411

Fax: ++39/02/70631911

francesco.prada@

istituto-besta.it

\section{Abstract \\ $\nabla$}

Purpose: Brain shift and tissue deformation during surgery for intracranial lesions are the main actual limitations of neuro-navigation (NN), which currently relies mainly on preoperative imaging. Ultrasound (US), being a real-time imaging modality, is becoming progressively more widespread during neurosurgical procedures, but most neurosurgeons, trained on axial computed tomography (CT) and magnetic resonance imaging (MRI) slices, lack specific US training and have difficulties recognizing anatomic structures with the same confidence as in preoperative imaging. Therefore real-time intraoperative fusion imaging (FI) between preoperative imaging and intraoperative ultrasound (ioUS) for virtual navigation (VN) is highly desirable. We describe our procedure for real-time navigation during surgery for different cerebral lesions.

Materials and Methods: We performed fusion imaging with virtual navigation for patients undergoing surgery for brain lesion removal using an ultrasound-based real-time neuro-navigation system that fuses intraoperative cerebral ultrasound with preoperative MRI and simultaneously displays an MRI slice coplanar to an ioUS image.

Results: 58 patients underwent surgery at our institution for intracranial lesion removal with image guidance using a US system equipped with fusion imaging for neuro-navigation. In all cases the initial (external) registration error obtained by the corresponding anatomical landmark procedure was below $2 \mathrm{~mm}$ and the craniotomy was correctly placed. The transdural window gave satisfactory US image quality and the lesion was always detectable and measurable on both axes. Brain shift/deformation correction has been successfully employed in 42 cases to restore the co-registration during surgery. The accuracy of ioUS/MRI fusion/ overlapping was confirmed intraoperatively under direct visualization of anatomic landmarks and the error was $<3 \mathrm{~mm}$ in all cases $(100 \%)$.

\section{Zusammenfassung \\ $\nabla$}

Ziel: Brain Shift und Gewebeverschiebung während der chirurgischen Entfernung intrakranialer Raumforderungen sind die limitierenden Faktoren bei der Neuronavigation (NN), welche aktuell hauptsächlich präoperative Bilder einsetzt. Ultraschall (US) als Echtzeit-Bildgebung wird bei neurochirurgischen Prozeduren zunehmend angewandt. Vielen Neurochirurgen fehlt aber die US Expertise, da schon in der Ausbildung standarisierte (typisch axiale) CT und MRT Schnittbilder für die Navigation bevorzugt eingesetzt werden und somit die Sicherheit bei der sonografischen Identifikation anatomischer Strukturen fehlt. Daher ist eine intraoperative Echtzeitfusion zwischen präoperativen CT bzw. MRT Bildern und intraoperativem Ultraschall (ioUS) im Rahmen der virtuellen Navigation (VN) außerordentlich wünschenswert. Wir präsentieren hier die bei uns angewandte Methode für dieEchtzeitnavigation bei der Entfernung verschiedener Hirntumoren.

Material und Methoden: Wir wandten die Bildfusion mit virtueller Navigation bei der chirurgischen Entfernung von Hirntumoren an. Zum Einsatz kam ein Neuronavigationssystem, welches intraoperative Ultraschallbilder mit präoperativen MRT Bildern in Echtzeit überlagert und zu jedem US Bild simultan die dazu passende ko-planare MRTSchnittebene anzeigt.

Ergebnisse: Die US-basierte Neuronavigation wurde bei der Operation von 58 Patienten mit Hirntumoren eingesetzt. In allen Fällen war der Fehler der initialen (externen) Registrierung, welche anhand von anatomischen Landmarken erfolgte, unterhalb von $2 \mathrm{~mm}$ und die Kraniotomie konnte korrekt angesetzt werden. Die Bildqualität des transduralen Ultraschalls war gut und die Läsion konnte bei allen Patienten detektiert und in allen Achsen vermessen werden. Die Korrektur von Brain Shift sowie Gewebeverschiebung gelang erfolgreich in 42 Fällen zur Wiederherstel- 
Conclusion: Neuro-navigation using intraoperative US integrated with preoperative MRI is reliable, accurate and user-friendly. Moreover, the adjustments are very helpful in correcting brain shift and tissue distortion. This integrated system allows true real-time feedback during surgery and is less expensive and time-consuming than other intraoperative imaging techniques, offering high precision and orientation. lung der intraoperativen Co-Registrierung. Die Genauigkeit der Überlagerung von ioUS und MRT wurde intraoperativ anhand der Visualisierung anatomischerLandmarken überprüft und der Fehler lag in allen Fällen (100\%) unterhalb von 3mm.

Schlussfolgerung: Neuronavigation mit Hilfe von in präoperative MRT Bilder integrierten intraoperativen US Bildern ist eine zuverlässige, genaue und anwenderfreundliche neue Technologie. Brain Shift und Gewebeverlagerungen können anhand verschiedener Einstellungsmöglichkeiten am System erfolgreich intraoperativ korrigiert werden. Das integrierte System ermöglicht eine intraoperative Überprüfung der Navigation in Echtzeit und ist dabei kostengünstiger und weniger Zeit aufwändig als andere intraoperative Bild-gebende Verfahren, trotzdem aber hoch präzise.

\section{Introduction}

Neuronavigation systems are valuable tools of routine use in neurosurgery, but they suffer from various limitations [1]. The most prominent is that they are based on preoperative images. Therefore, they have to be considered as being not true real-time systems. It is mandatory to remember that the accuracy of such systems during surgery is maximal before the craniotomy and decreases significantly with the progress of surgical manipulation. System accuracy reduction related to parenchymal and vascular structure changes is severe and inevitable, and it is due to two main factors: the first is "brain shift" caused by the effect of gravity on the brain, brain swelling, as well as the escape of cerebrospinal fluid (CSF); the second is due to brain parenchyma deformation caused by surgical maneuvers and tumor removal [2 -4].

Intraoperative MRI (iMRI) and/or CT (iCT) are/is able to update intraoperative imaging and have/has been introduced in order to counteract the effect of brain shift and brain deformation. Positive aspects of these systems are the spatial resolution, the width of the field, and the absence of anatomic limitations. Major drawbacks are that they are quite expensive and time and space-consuming. Furthermore, it is not possible to operate under direct and continuous imaging guidance. Therefore, they still cannot be considered as true real-time intraoperative imaging systems [5]. Intraoperative ultrasound (ioUS) imaging during neurosurgical procedures is becoming progressively more widespread and multiple studies have shown that US is a valuable tool in tumor detection during surgery [6-8]. The main advantage of US scanning lies in the real-time characteristics of the imaging, the ease and repeatability of use and its contained costs, especially compared to iCT or iMRI scanner. However, ultrasound imaging is limited in its field of view, typically shows a different plane than the standard axial plane displayed by CT and MRI, and its spatial resolution and image quality depend on the ability of the user. The ability to "understand and interpret" anatomic image details displayed on the screen requires significant training and experience and is therefore highly operator-dependent [9]. Because most neurosurgeons do not receive specific US training and because US is not yet a standard diagnostic or intraoperative imaging tool for cerebral lesions, there is an inherent difficulty in interpreting ioUS imaging and in the correct setup of the machine parameters, both factors leading to a longer learning curve.

Real-time intraoperative fusion imaging between preoperative imaging and intraoperative ultrasound for surgical navigation is a highly desirable solution to the above-mentioned problems $[10,11]$. Here we present in detail the technique we use in prac- tice for patients undergoing surgery for brain lesion removal with a US system that uses the so-called "Virtual Navigation" (VN) technology, which fuses the intraoperative ultrasound images with a reference modality (preoperative MRI), emphasizing the positive aspects of this approach.

\section{Materials and methods \\ $\nabla$}

Patient population and system architecture:

We evaluated patients bearing tumor-like brain masses which were deemed surgically resectable. Patients underwent surgery for brain lesion removal with image guidance using a US system equipped with Virtual Navigator allowing fusion imaging for neuronavigation. All patients were thoroughly informed regarding the procedure they were going to undergo and written consent was obtained.

To acquire the preoperative reference images, volumetric T1weighted contrast-enhanced MRI (Siemens, Germany) is generally used. We used a last generation US device (MyLab, Esaote, Italy) equipped with a corresponding software application for Virtual Navigation (MedCom, Germany). The probe employed is a variable band linear array with an operating bandwidth of $11-3 \mathrm{MHz}$ (LA332, Esaote, Italy), covered with a sterile probe cover (Civco, USA), as the intraoperative US scanner. The tracking system consists of a magnetic transmitter positioned on a dedicated support next to the patient's head, a receiver to be attached to the US probe during navigation, and a tracked pointer also equipped by a magnetic receiver used during the initial registration $(\bullet$ Fig. 1,2 ). The VN system provides the position and orientation of the US probe and the pointer in relation to the transmitter in the $3 \mathrm{D}$ coordinate system of the transmitter, where an oblique plane generated by free-hand moving of the probe in a $3 \mathrm{D}$ space is displayed as an oblique cut through the co-registered $3 \mathrm{D}$ MRI dataset in order to calculate virtual 2 D MRI images, which are coplanar to the current US imaging plane.

\section{Preoperative procedure and initial registration}

The first step is to scan the patient with the reference modality (MRI). MRI scans are transferred to the navigation system in DICOM format using LAN network. The VN unit processes every slice, taking into account the (sometimes unequal) slice thickness and spacing, and generates a homogeneous $3 \mathrm{D}$ volume out of them, showing the three orthogonal planes on which the surgical planning is performed as with any standard NN system ( $\bullet$ Fig. 3 ). 

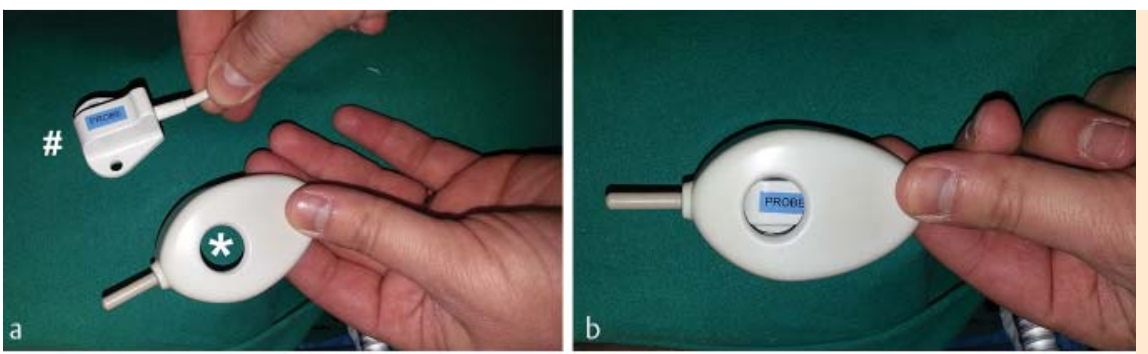

Fig. 1 a receiver (\#) and pointer (asterisk); b receiver applied to pointer; $\mathbf{c} U S$ linear probe (\#) [Esaote LA332]); $\mathbf{d}$ receiver applied to probe.

Abb. 1 a Empfänger (\#) und Pointer (Stern); b Empfänger auf den Pointer appliziert; $\mathbf{c}$ US Linearsonde (\#) [Esaote LA332]); d Empfänger auf die Sonde appliziert.
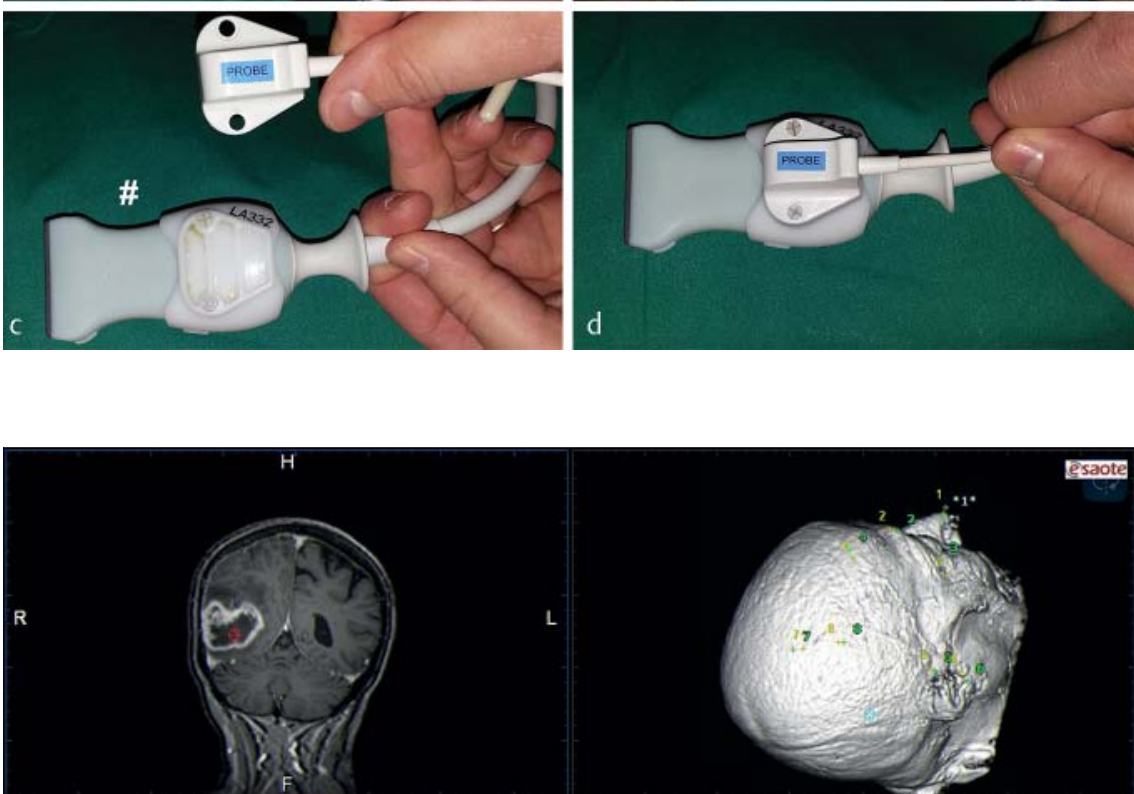

A

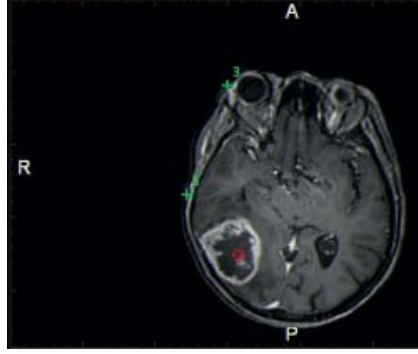

A
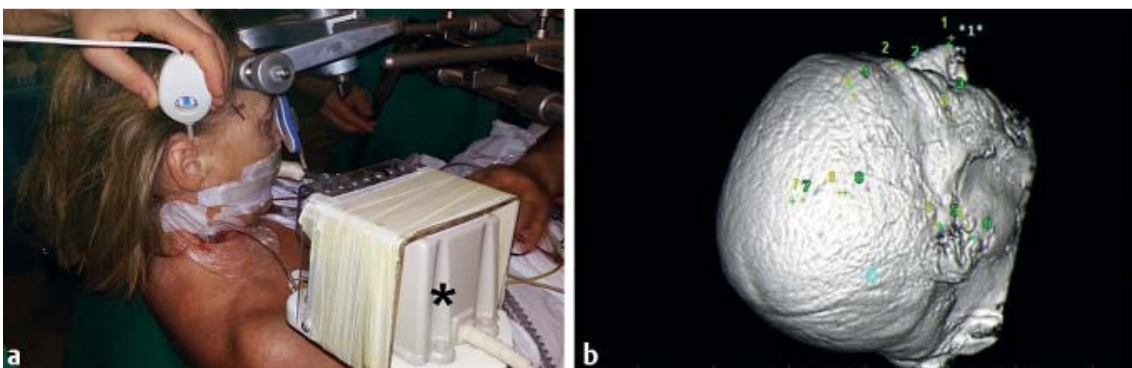

Fig. 3 a patient positioning with magnetic field emitter (asterisk) fixed to the operating table; $\mathbf{b}$ co-registration between chosen anatomical landmarks of the patient in the $3 \mathrm{D}$ frame and the anatomical landmarks defined on the MRI volume rendering on the VN unit.

Abb.3 a Patient mit positionierten Magnetfeld-Emittern (Stern), auf dem Operationstisch fixiert; b Co-Registrierung der gewählten anatomischen Landmarken des Patienten im 3D-Frame und die im MRT-Volumen-Rendering definierten anatomischen Landmarken in der VN-Unit.

The patient is positioned on the surgical table and the head is fixed with a three-pin head-holder. The transmitter is then mounted on a static support bonded to the surgical table. The transmitter, whose position is considered the origin of the reference system, is kept stationary oriented toward the patient head by a proper fixation support, while the actual position and orien- tation of the US probe and/or the pointer, moving freely in the generated three-dimensional ( $3 \mathrm{D}$ ) space, is provided by the receiver attached on the instrument. This tracking system generates an electromagnetic field, which is strongest at the transmitter site and attenuates with distance. The total operative range is $70 \mathrm{~cm}$. However, since the highest accuracy is achievable close to 
the transmitter, the transmitter is placed $15-20 \mathrm{~cm}$ away from the head of the examined subject ( 0 Fig. 2 ). In contrast to optical tracking systems, free line-of-sight is not requested when using electromagnetic tracking. On the other hand, some care has to be taken to avoid the presence of large metallic objects between the transmitter and tracked instruments. This requirement can be typically fulfilled easily.

The registration procedure of the MRI volume and the real-time US scan consists of two phases: initial registration and fine-tuning. The initial rigid registration is performed before sterile patient draping. Since we are not yet in a strictly sterile environment, the surgeon or an assistant performs this procedure. It is based on the identification of external anatomical landmark correspondences, whereas anatomic or external fiducials can be used. Fiducial markers are very easy to identify, but have to be fixed to the skin before MRI examination and must remain there until the day of operation. This is neither comfortable for the patient nor always possible, in addition the skin can move in relation to the skull, or the fiducials themselves might move. Therefore, fiducials are not commonly used and NN systems typically use eight anatomical landmarks selected on the skull surface (tip of the nose and glabella on the midline; lateral canthus, tragus, ear attachment bilaterally). For this purpose the receiver of the tracking system is attached to the registration pen and is used to click on the anatomical landmarks on the patient's skin matching them with the same points defined on the MRI volume rendering on the US system ( $\bullet$ Fig. 2 ). This procedure, performed only at the beginning of the operation, is completed typically within 1 2 minutes.

The aim of this initial registration, performed with closed skull and using only one imaging modality (MRI), is to align both the current patient's position and orientation and the $3 \mathrm{D}$ MRI dataset in relation to the fixed reference coordinate system, where the magnetic transmitter is the origin. When all anatomical landmarks, defined on the MRI reconstructed surface, are paired with the corresponding points on the patient, acquired with the pointer tool, the system calculates a so-called "rigid registration matrix". Rigid registration is eligible before craniotomy, since the skull bone behaves like a rigid body. Using this matrix, it is possible now to correlate the oblique transducer spatial position (and the corresponding US image) with the related reference imaging modality. For this purpose the receiver is now mounted on the US probe. Before performing the craniotomy, we usually check the accuracy of the initial registration and of the system probe-receiver by using the US probe temporarily as "pointer" matching some external anatomical landmarks on the patient with the same points on the volume surface created by the system. To do this, we use the midpoint of the linear US probe as the "tip of an NN pointer". Once the accuracy of the system has been verified, either the navigated US probe or the pointer itself can be used as a drawing instrument in order to navigate and plan the craniotomy (๑ Fig. 4).

Intraoperative fine-tuning procedure and data analysis The second level of the registration phase (fine-tuning) is carried out during surgery.

The patient is draped and sterile conditions are set, the US probe is covered with sterile plastic probe cover coupled with ultrasound gel (Civco, USA) and the craniotomy is performed under navigation guidance. The dials of the ultrasound device are also covered with a transparent plastic sheath and can be operated di- rectly by the surgeon, in order to obtain an adequate ultrasound image.

After bone flap removal but before opening the dura mater, we might expect brain shift to occur, but no brain deformation yet. The brain is changing its location with respect to the skull as seen in the preoperative images. However, the brain shape as a whole remains de facto unchanged. The initial registration was performed on external skull landmarks, thus this brain shift effect results in a registration misalignment. For compensating this misalignment, fine-tuning registration is now performed. By placing the US probe directly on the dura, the brain and the lesion are scanned with a standard B-mode US modality and anatomic details from the interior of the brain become clearly visible (० Fig. 5).

Based on the initial registration, the US imaging and the correspondent preoperative MRI are displayed on the screen of the Virtual Navigation system and are merged together by means of over-blending ( $\bullet$ Fig. 6 ). The main task here is to identify some visible brain structures both on US and MRI images and visually evaluate on the superimposed image if the corresponding structures are aligned, indicating a perfect match. Again, we do not require a perfect US image here, and it is sufficient to visualize some characteristic landmarks. Thanks to this feature, it is possible to visually evaluate the accuracy of the initial registration looking for misalignment of major anatomical structures such as ventricles, vessels, mid-brain, dural structures between the MRI image and the real-time US image. If a location difference between the real position of a structure (assessed by US image) and the position of the same anatomic detail according to the Virtual Navigation system is observed, the error is measured and might be corrected in two ways:

- In-plane correction: If the same characteristic landmark is visible on both images, freeze the displayed US and MRI images on the screen, then drag/shift/rotate one image with the mouse to the correct position over the other.

- Out-of-plane correction: If no common landmarks are visible, select one or more clearly visible anatomic landmark(s) on one of the modalities, freeze said image and move the probe until the other (still moving) modality displays the same information as the frozen one; clicking on the same anatomic landmark in both images automatically matches both modalities (॰ Fig. 7).

This fine-tuning step is performed whenever needed, typically several times during the operation. During the resection of the mass, additional brain distortions appear. Such distortions can be visually detected on US and corrected any time by repeating one of the two above-mentioned possibilities ( $\bullet$ Fig. 7 ). The proximity of other structures and the surgical cavity can be visualized as well ( $\bullet$ Fig. 8). Fine-tuning is intuitive and fast. The surgeon operates the transducer and performs the corrections on the US console. In-plane correction is trivial and can be performed within a few seconds. Out-of-plane correction takes longer, since the surgeon has to move the probe until the requested anatomic landmark, which is already visible on MRI, becomes visible also on US. Nevertheless, this task is also completed typically within less than a minute.

Once fine-tuning is completed, navigation is started. On the screen the image from the US probe merged with the corresponding oblique co-planar preoperative MRI is visualized, helping to recognize structures thanks to the real-time update and comparison and the typically higher anatomic clarity of MRI images. 


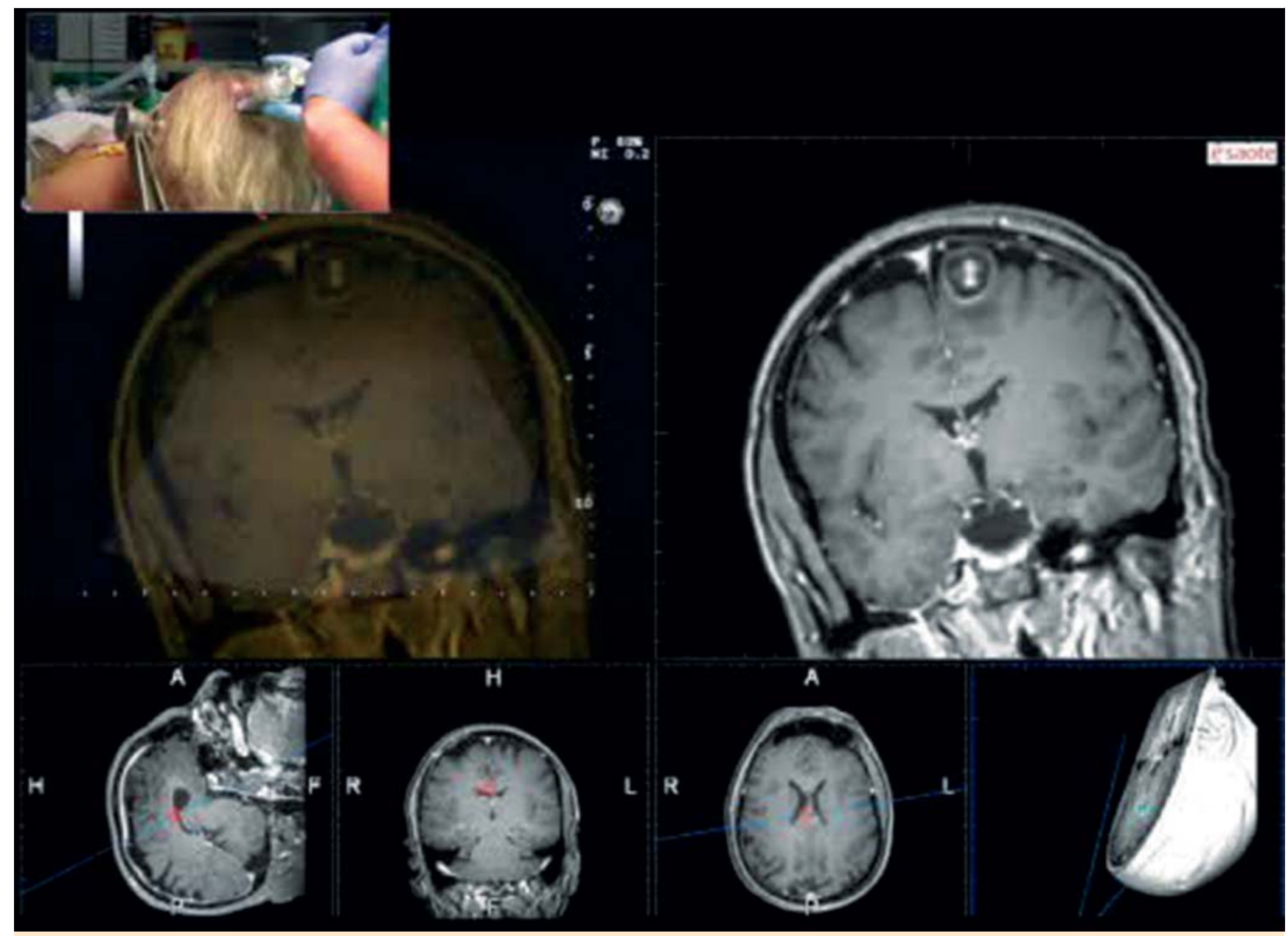

Fig. 4 Craniotomy planning using the navigated US probe (superimposed frame, superior left hand corner). In the VN unit screenshot it is possible to visualize the MRI-based coronal visualization of a right frontal pre-motor mesial cystic lesion in the right portion of the screen. The left portion of the screen is devoted to US imaging, which is not visualized because of bone shielding. In the inferior portion of the screen, the different planes (sagittal, coronal, axial, plane of probe) are depicted.

Abb. 4 Planung einer Kraniotomie unter Verwendung einer navigierten US-Sonde (darüber gelegter Rahmen, obere linke Ecke). Im VN-UnitScreenshot ist es möglich die MRT-basierte koronale Darstellung einer rechtsfronalen prämotorisch-mesialen zystischen Läsion im rechten Bereich des Monitors sichtbar zu machen. Im linken Abschnitt des Monitors das USBild, das wegen der Abschirmung des Knochens nicht darzustellen ist. Im unteren Bereich des Monitors sind die verschiedenen Ebenen (sagittale, koronale, axiale Ebene der Sonde) abgebildet.

An advanced imaging technique (for both MRI and US) can also be used. Functional MRI (fMRI) and diffusion tensor imaging (DTI) dataset might be added and fused to the standard MRI sequences ( $\bullet$ Fig. 9) used for navigation purposes and linked to iUS imaging. Contrast-enhanced ultrasound (CEUS) can also be performed and visualized linked to MRI (๑ Fig. 10).

In addition to online navigation, the system offers several quality control tools for retrospective analysis: multiple images and cine-clips can be obtained and stored, data regarding brain shift and distortion and subsequent intraoperative adjustments are recorded, intraoperative qualitative analysis is performed by comparing B-mode US imaging and pre-acquired MRI images. By using these tools, an offline interobserver quantitative analysis has been performed to evaluate the precision of the system. Prior to the start of surgery, the distance between the crosshair and a given anatomical landmark ("initial accuracy") is measured. After removal of the bone flap, a second measurement is performed, scanning the lesion to assess brain shift or brain deformation ("surgical accuracy").

\section{Results}

\section{$\nabla$}

We intraoperatively evaluated 58 patients (age range: $10-76$ years; mean: 50 years), who were harboring different intracranial lesions ( 41 gliomas, 8 metastases, 6 meningiomas, 2 cavernoma, 1 ependymoma), undergoing surgery for lesion removal (৫ Table 1). For all 58 examinations, the initial registration error obtained by the corresponding anatomical landmark procedure was below $2 \mathrm{~mm}$. The initial accuracy measured with the registration pen was always less than $2 \mathrm{~mm}$. In all cases the craniotomy was correctly placed, the transdural window gave satisfactory US image quality and the lesion was always detectable and measurable on all axes.

The major internal anatomical landmarks used for fine-tuning were: falx cerebri $(\mathrm{FC})$, tentorium $(\mathrm{T})$, lateral ventricles $(\mathrm{LV})$, third ventricle (TV), choroid plexus (CP), mesencephalon (M). We used the middle cerebral artery (MCA), basilar artery (BA) and posterior cerebral artery (PCA) as vascular landmarks. Other useful more superficial landmarks were the peri-lesional arachnoidal fold (PAF) and sylvian fissure (SF) (৫ Fig. 11). Due to anatomical 


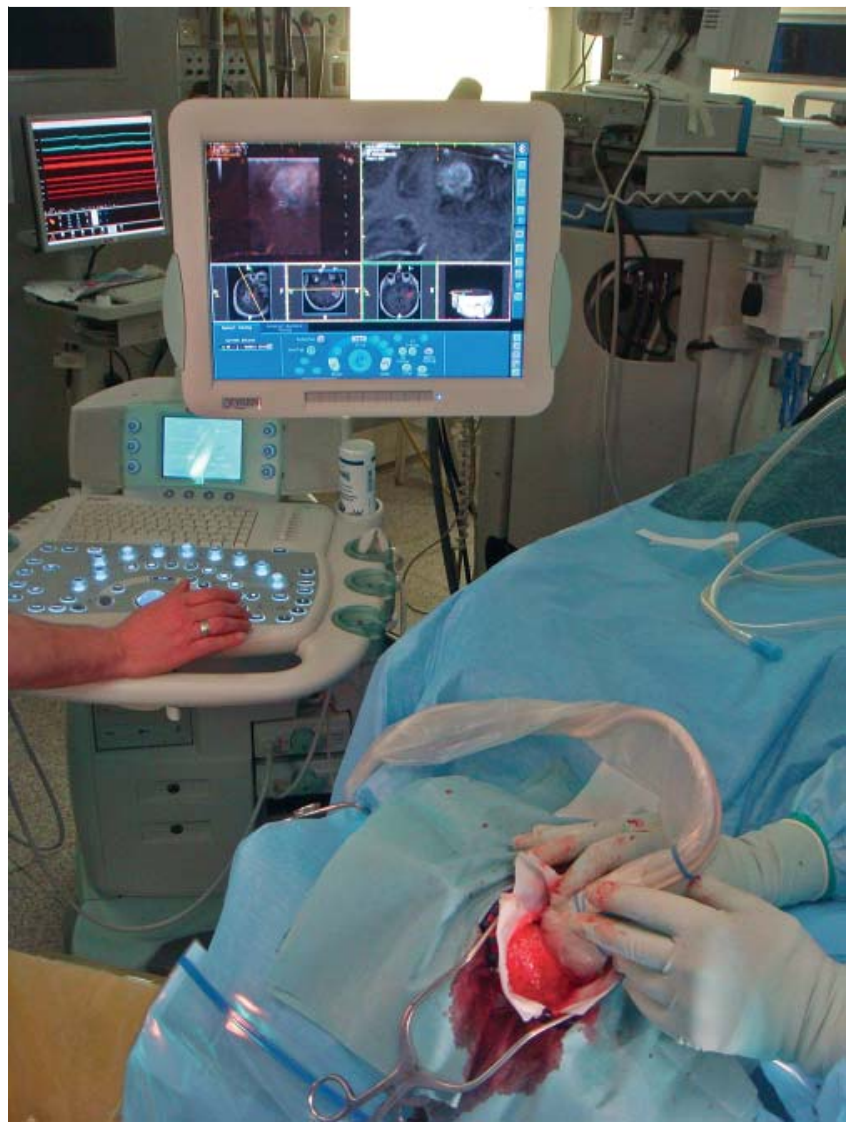

Fig. 5 Intraoperative procedure: after bone flap removal, transdural insonation is performed. Two-axis standard B-mode evaluation of the lesion and first comparison between intraoperative US and preoperative MRI imaging are performed, assessing fusion accuracy.

Abb. 5 Intraoperatives Verfahren: Nach Entfernung der Knochenplatte wird durch die Dura mater geschallt. Eine zweiachsige standardisierte BBildbewertung der Läsion und ein erster Vergleich zwischen intraoperativem US und präoperativer MRT zur Beurteilung der Fusionsgenauigkeit wird durchgeführt.

differences and surgery location, different subsets of landmarks were targeted to evaluate brain shift due to probe pressure and gravity effect, and tissue deformation caused by tumor resection and parenchyma re-expansion, accordingly.

After bone flap removal, we found a mismatch (brain shift) larger than $4 \mathrm{~mm}$ in 42 of the 58 cases. After craniotomy as well as during surgery, we recalibrated by means of the fine-tuning functionality in all 58 cases, de facto never relying on the initial registration after craniotomy! During tumor resection (brain deformation), multiple views of the surgical field were performed in order to assess tumor residuals and visualize the cavity. After complete resection, the area was scanned for documentation purposes, to examine the cavity for tumor remnants and brain parenchyma re-expansion, evaluating it in all 58 cases.

\section{Representative Case}

\section{$\nabla$}

A 62-year-old woman with a previous history of lung neoplasm was admitted to our institution without any symptoms, harboring a right posterior frontal pre-motor cystic lesion discovered during follow-up. Surgery was performed through a right parietal paramedian craniotomy that was planned using the virtual navigation system. After removal of the bone flap and prior to incision of the dura, a first fine-tuning was performed. Even though the dura was closed, the brain shift was appreciable. At this time in the surgery, we were able to compare the anatomy of preoperative MRI to that of real-time US imaging, overlapping the two imaging modalities and understanding it in detail. After dural incision, we started to resect the lesion. After partial tumor removal, the brain shift was again evaluated. At this point of the removal, the brain shift and especially brain deformation became so severe that fine-tuning was no longer possible due to the non-elastic deformation of the brain caused by tumor removal. Thus, for the remaining part of the operation, our operative field examination was based on US imaging solely, while the corresponding MRI plane was used as supportive qualitative orientation context. After 24 hours the patient underwent post-operative MRI, which showed lesion excision with no complications. The post-operative period was uneventful and the patient was discharged without any neurological deficit (video 1 ).

\section{Discussion}

Conventional neuronavigation systems are a standard tool in the planning and performing of a craniotomy [12]. Neuronavigation is based on preoperative MRI with all its positive features: spatial resolution, width of field, absence of anatomic limitations, and the familiarity of neurosurgeons with this imaging technique. Its main limitation is due to the fact that it is based on preoperative imaging that cannot be updated intra-operatively, so it does not take into account dynamic phenomena such as brain shift, brain deformation (retractors, spatula, and surgical maneuvers), tissue resection and parenchyma re-expansion. Once the bone flap has been removed, brain shift takes place, affecting neuronavigation references and making it less accurate for fine recognition of anatomical landmarks. Even if it would be possible to correct initial brain shift over and over again during surgery, it is not possible to fix the brain deformation that inevitably takes place through surgical manipulation. Consequently, these factors cause the preoperative images to be inadequate in describing the real anatomic situation during surgery.

The advantages of US B-mode imaging are that it is a repeatable, fast, cheap, generally available, manually free moving, real-time imaging modality. Nevertheless, its limited field of view, the unusual plane of insonation, its image quality, and the dependency on operator skill and training make it difficult to interpret.

Fusion imaging is a particularly useful tool since it combines the benefits of two imaging modalities, thus overcoming the limitations of both. Coupling these two techniques exceeds the limitations of each technique alone and introduces a new approach to surgery. Fusion imaging was first developed by radiologists for the ablation of hepatic neoplasms or lesions $[13,14]$. The methodology consists of performing a US-guided minimally invasive (e.g. RF ablation) procedure merging the iUS imaging with CT or other modalities in order to target hepatic lesions, especially when characterized by poor sonographic conspicuity [15]. Over the years this has been shown to be a very reliable and successful approach [16-20]. US images map the current anatomic situation in real time, but lack the anatomic clarity of MRI scans. In other words, preoperative MRI should help in understanding US images, always keeping in mind that only US images are really faithful to the actual intraoperative anatomy, showing in real 


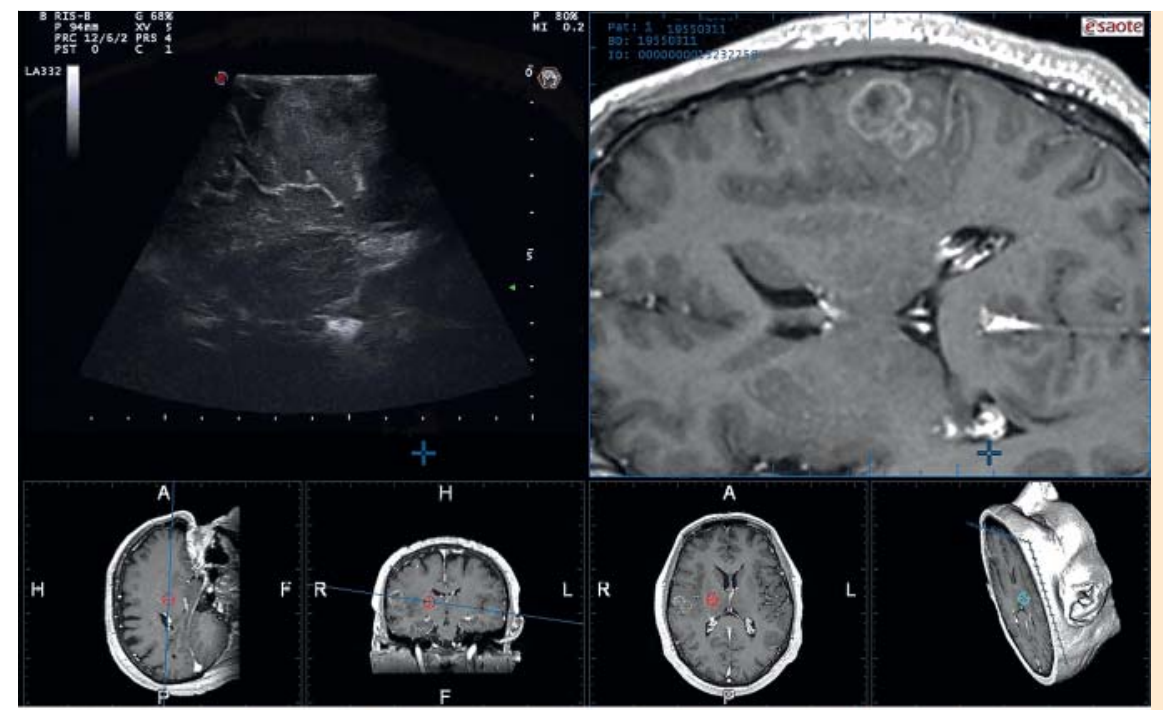

Fig. 6 Navigation with both modalities is performed (upper screenshot). Superimposition of one modality on the other is also performed, to check correlation accuracy.

Abb. 6 Durchführung der Navigation mit beiden Modalitäten (oberer Screenshot). Die Überlagerung von einer Modalität mit der anderen wird auch durchgeführt, um die Korrelationsgenauigkeit zu überprüfen.

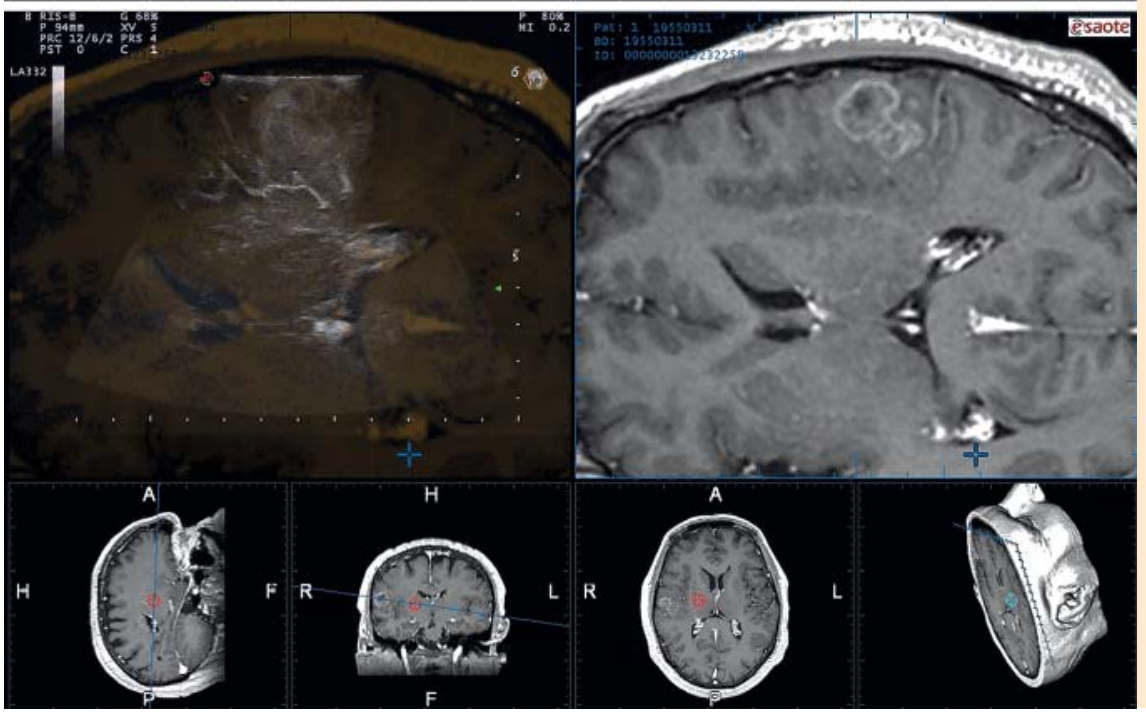

time the degree of excision, residual mass or proximity to other structures.

In the past other authors described ioUS to correct the shift during surgery. In 1997, Richard D. Bucholz et al., using and ioUS scanner linked with a navigator, measured the shift of the anatomical structure during various surgeries, identifying structures with a high, moderate, and low level of shift. On this basis he built up a model of response of the brain to surgery in order to correct the brain shift in an automated fashion [21]. In 2000, Roch M. Comeau et al. published a surgical guidance system that incorporates preoperative images (e. g. MRI) with intraoperative US imaging to detect and correct brain tissue deformation during surgery. In that paper the authors validated the system accuracy using a deformable multi-modality imaging phantom [22]. In 2004, J. R. Schlaier et al. combined two commercial systems, an $\mathrm{NN}$ and an US scanner to obtain a navigated US scanner. In their paper the authors evaluated the accuracy of the system observing that it is possible to achieve a highly accurate system but careful interpretation is needed when different angles and distances of the US probe to the object are concerned [23]. In 2007, Javier Gonzalez et al. proposed a method for brain shift correction based on a $3 \mathrm{D}$ US scanner linked to a neuronavigation system. They proposed using a landmark-based transformation algorithm that can be employed in real time during surgery.
Evaluating this method in a real phantom that mimics the properties of real brain tissues, the author states that the method could be improved but it can be successfully applied [24].

However, all of these authors started from the necessity to correct the brain shift in order to use navigation during the entire surgery. To do this, they analyzed various methods including iMRI, iCT and ioUS, concluding that today the latter has the best cost-effectiveness ratio. In other words they consider ioUS as a tool to update neuronavigation. We started from a different point. In our group we gathered B-mode $2 \mathrm{D}$ ioUS experience as an imaging tool initially independent of neuronavigation. We have already described the use of contrast-enhanced intraoperative US (CEUS) in order to study the vascular supply and the perfusion pattern of the lesion and also to grade the glial tumor [25, 26]. Having a positive previous experience and "a trust" in the application of ioUS, we asked ourselves how to enhance the information obtainable from US scan further. Our first goal was to improve the usage and eliminate the drawbacks of NN by intuitively and quickly correcting brain shift. Our second goal, going beyond classic neuronavigation, was to improve spatial orientation in the brain during all phases of operation, tumor localization, and, finally, US image understanding even for the untrained neurosurgeon. 

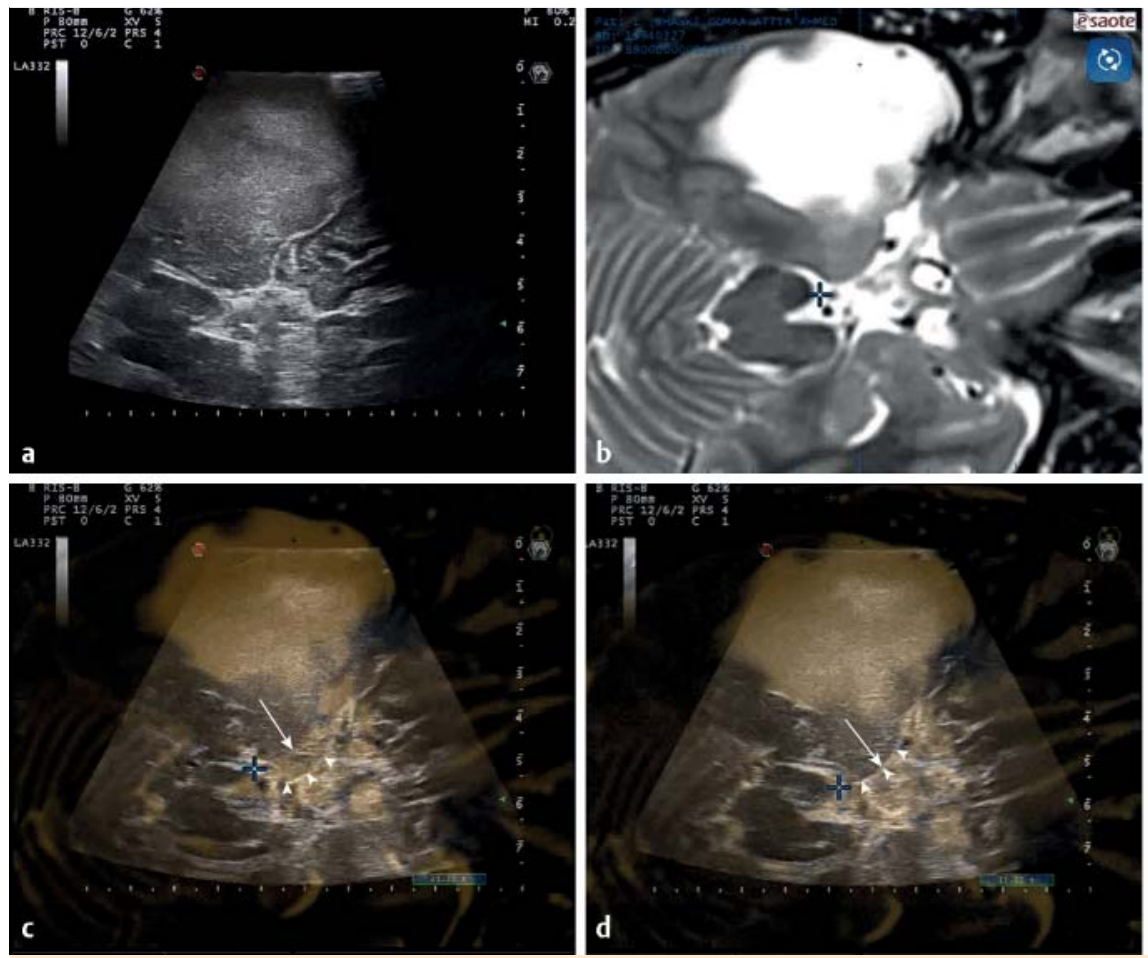

Fig. 7 Intraoperative US a and MRI b view in a case of left temporal lowgrade glioma. In c, d, a merged view between US and MRI is displayed. In c, a vertical misalignment (> $4 \mathrm{~mm}$ ) is visible, mid-brain (blue crosshair) and mesial temporal structures are not correlated in US and MRI (arachnoidal interfaces of the uncus on US [arrow head] are not aligned to the correspondent structure on MRI [arrow]). Brain shift and tissue distortion correction is performed: in panel $d$ the US imaging has been frozen and the MRI has been manually adjusted to fix the error and recalibrate the system (visual re-alignment of hyperechoic arachnoidal layer of the uncus on US [arrow head] with uncus profile on MRI [arrow]).
There is no doubt that most neurosurgeons are not familiar with US imaging, probably because of a lack of use in the preoperative diagnostic process, a lack of inclusion in the surgery training curriculum, or also because of an unquestionably lower quality of the US images in the past. Moreover, despite the increasing use of ioUS in the (neuro)surgical field, few neurosurgeons have received specific US training. Therefore, there is an inherent difficulty in recognizing the images produced by US, and this leads to a greater learning curve. It is important to emphasize here that the current system does not require an "optimal" US image of highest diagnostic quality, but an "adequate" image, i.e. one where the anatomic details to be used in the fine-tune and navigation steps are clear enough. Although modern US devices typically offer a plurality of various tuning possibilities, we experienced that only very few of them truly have to be individually adjusted:

1. Gain, to regulate the image luminosity.

2. Depth, to define how deep the US penetrates the brain (to see superficial or deep structures).

3. Contrast, to regulate the intensity difference between light and dark areas of the image.

These are by far the most important ones and are typically adjusted in each different case.

"Advanced users" may also manipulate two additional parameters:
Abb.7 Intraoperativer US a und MRT b bei einem Fall mit linkstemporalem, geringgradigem Gliom. Feld $\mathbf{c}$, $\mathbf{d}$ zeigen eine fusionierte Ansicht von US und MRT. Bei c ist ein vertikaler Ausrichtungsfehler (> $4 \mathrm{~mm}$ ) zu sehen, das Mittelhirn (blaues Fadenkreuz) und die mesialen temporalen Strukturen stimmen im US und in der MRT nicht überein (arachnoidale Verbindungen des Uncus im US [Pfeilspitze] sind nicht zu den korrespondierenden Strukturen im MRT [Pfeil] ausgerichtet). Eine Korrektur von Brain Shift und Gewebedeformation wird durchgeführt: Im Feld $\mathbf{d}$ wurde das US-Bild eingefroren (statt eines Standbildes) und das MRT wurde manuell justiert, um den Fehler zu beheben und das System zu rekalibrieren (visuelle WiederAusrichtung der hyperechogenen arachnoidalen Schicht des Uncus im US [Pfeilspitze] mit dem Uncusprofil im MRT [Pfeil]).

1. Focus, to define the area where US imaging appears sharpest. It is set typically on the anatomic detail to be adjusted next.

2. Filtering, to adapt the look-and-feel of the image. Some users prefer a rather smooth image, while others like a crisper one. It is a matter of personal preference, and users typically pick their favorite and then don't change the setting anymore.

However, their importance is rather a subject of personal preference and not a mandatory image improvement. In our experience every user can learn to adjust the aforementioned parameters after minimal training. The complexity is low and therefore the learning curve when operating the US device is truly steep.

Two factors are important to explain this:

- First, the probe is in direct contact with the soft and quite homogeneous brain tissue and has no hard obstacles like bone, etc. Moreover, the brain structures we are looking for are superficial and lie within $2-6 \mathrm{~cm}$. These are truly optimal conditions for US imaging and result by nature in a substantially easier situation as compared to effectively any other body organ, making US setup accordingly easier than for general abdominal examination.

- Second, the US images here are used for navigation and not for diagnosis. An "adequate" image is one showing all brain structures needed for navigation clearly enough to be identified by the user. The goal is to match these structures with MRI and 




Fig. 8 Comparison between scans before tumor resection (a surgical field view, probe placed in sterile plastic sheath, transdural scan. $\mathbf{b}$ US + VN screenshot) and after tumor resection (c surgical field view). d US + VN screenshot, with superimposition between US visualization of the surgical cavity outlined with [o] and preoperative MRI outlined with $[x]$, still showing the lesion, evaluating residual masses on US and tissue distortion.

Abb. 8 Vergleich der Scans vor Entfernung des Tumors (a chirurgischer Blick; Sonde in steriler Plastikhülle platziert; transduraler Scan. b US + VN Screenshot) und nach Entfernung des Tumors (c chirurgischer Blick; d US + VN Screenshot mit Überlagerung des US-Bildes der chirurgischen Kavität mit [o] markiert und dem präoperativen MRT mit $[x]$ markiert, die die Läsion noch zeigen, um die verbleibenden Raumforderungen im US und der Gewebedeformation zu beurteilen.

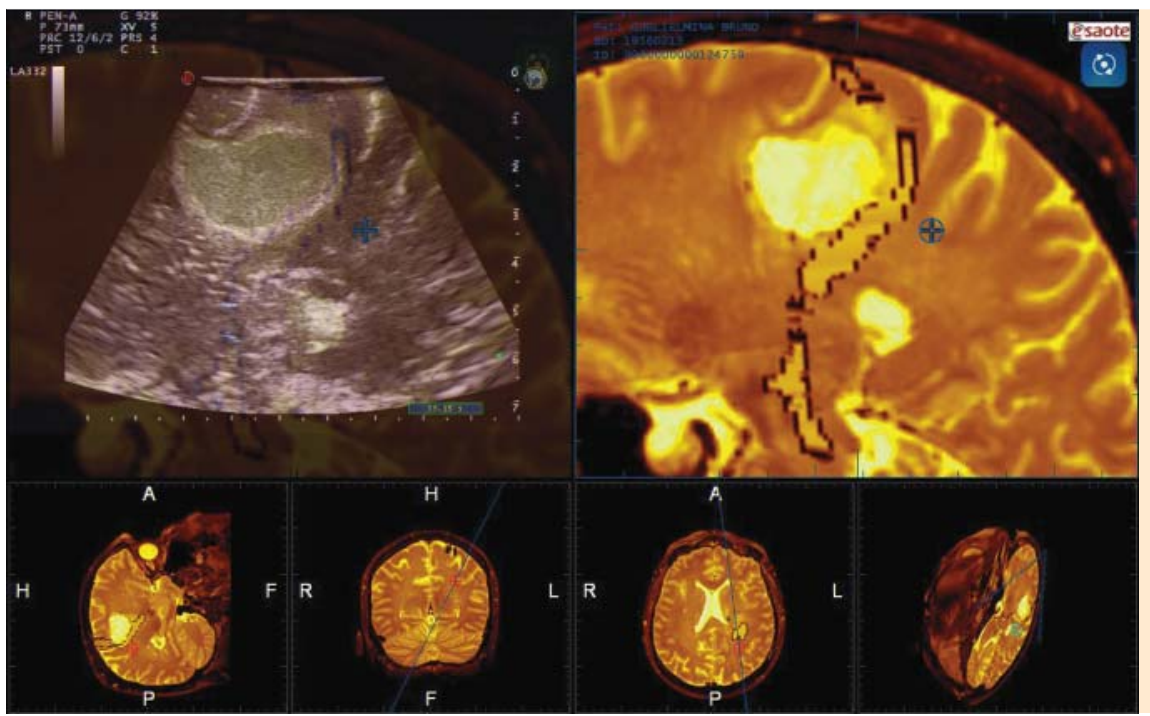

Fig.9 Virtual navigation and advanced MRI imaging: intraoperative screenshot depicting a posterior frontal high-grade glioma on the left side of the screen correlated to preoperative volumetric MRI with DTI on the right side of the screen. The corticospinal tract is highlighted on MRI and it is superimposed on the US image, thus allowing for real-time localization of functional areas.

Abb.9 Virtuelle Navigation und weiterentwickelte MRT-Bildgebung: Der intraoperative Screenshot zeigt posterio-frontal ein hochgradiges Gliom auf der linken Seite des Monitors in Korrelation zum präoperativen volumetrischen MRT mit DTI auf der rechten Monitorseite. Der Kortikospinaltrakt ist im MRT hervorgehoben und über das US-Bild gelagert und erlaubt somit die Lokalisierung funktioneller Bereiche in Echtzeit.

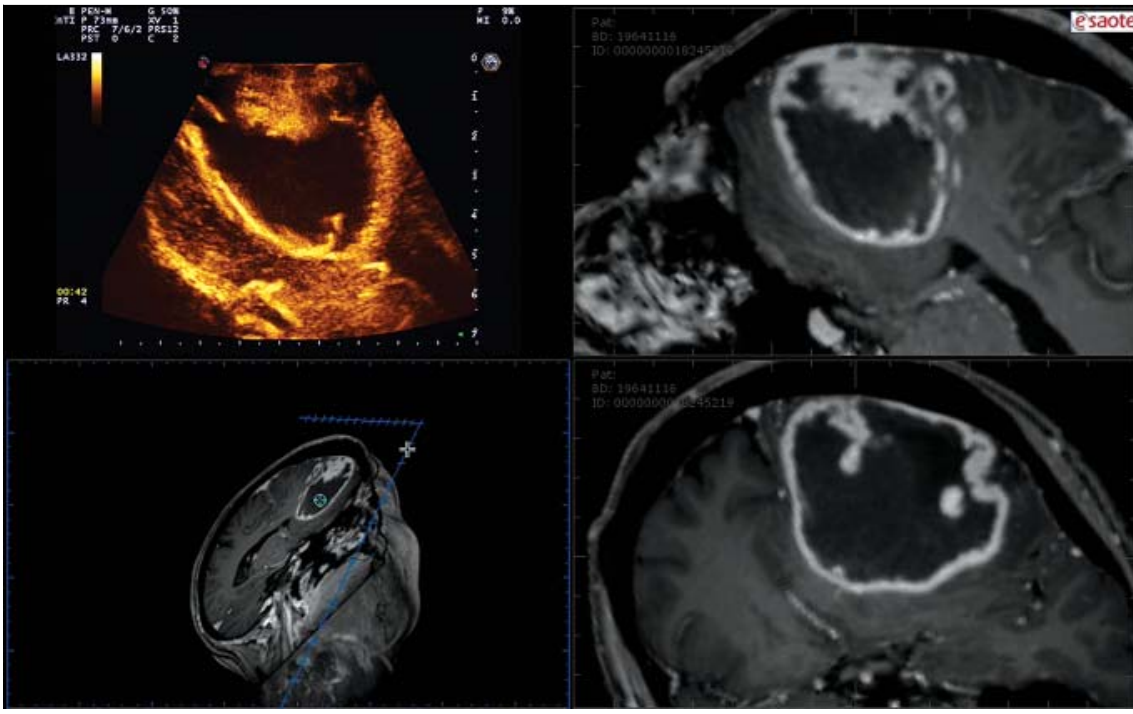

Fig. 10 Virtual navigation and advanced US imaging: intraoperative screenshot depicting a left frontal high-grade glioma highlighted with contrast-enhanced ultrasound (CEUS) on the left side of the screen correlated to preoperative T1 gadolinium-enhanced MRI on the right side of the screen.

Abb. 10 Virtuelle Navigation und weiterentwickelte US-Bildgebung: Der intraoperative Screenshot zeigt ein linksfrontales hochgradiges Gliom im kontrastverstärktem Ultraschall (CEUS) hervorgehoben auf der linken Monitorseite in Korrelation zum präoperativen T1-Gadolinium-verstärktem MRT auf der rechten Seite. 


\begin{tabular}{|c|c|c|c|c|c|}
\hline no. & sex & age & diagnosis & WHO grade & location \\
\hline \multicolumn{6}{|c|}{ low-grade gliomas } \\
\hline 1 & $\mathrm{~m}$ & 10 & pilocytic astrocytoma & I & left frontal \\
\hline 2 & $f$ & 25 & pilocytic astrocytoma & 1 & right temporal \\
\hline 3 & f & 36 & fibrillar astrocytoma (r) & II & left frontal \\
\hline 4 & $\mathrm{~m}$ & 49 & gemistocytic astrocytoma & II & left temporal \\
\hline 5 & $\mathrm{~m}$ & 62 & gemistocytic astrocytoma & II & left temporal \\
\hline 6 & $\mathrm{~m}$ & 31 & oligodendroglioma & II & right temporal \\
\hline 7 & $f$ & 26 & oligodendroglioma & II & left frontal \\
\hline 8 & $\mathrm{~m}$ & 42 & oligodendroglioma & II & left temporal \\
\hline 9 & $\mathrm{~m}$ & 41 & oligodendroglioma & II & left frontal \\
\hline 10 & $\mathrm{~m}$ & 52 & oligodendroglioma & II & right frontal \\
\hline 11 & $\mathrm{~m}$ & 60 & oligoastrocytoma & II & left parieto-occipital \\
\hline 12 & $\mathrm{~m}$ & 31 & oligoastrocytoma & II & right frontal \\
\hline 13 & $f$ & 57 & oligoastrocytoma & II & right temporal \\
\hline 14 & $\mathrm{f}$ & 34 & oligoastrocytoma & II & left temporal \\
\hline \multicolumn{6}{|c|}{ anaplastic gliomas } \\
\hline 15 & $f$ & 32 & anaplastic astrocytoma & III & left temporal \\
\hline 16 & $\mathrm{~m}$ & 63 & anaplastic astrocytoma & III & left temporal \\
\hline 17 & $f$ & 38 & anaplastic astrocytoma & III & left insular \\
\hline 18 & $\mathrm{~m}$ & 39 & anaplastic astrocytoma & III & left insular \\
\hline 19 & $f$ & 17 & anaplastic oligodendroglioma & III & left temporo-insular \\
\hline 20 & f & 35 & anaplastic oligodendroglioma & III & right frontal \\
\hline \multicolumn{6}{|c|}{ glioblastomas } \\
\hline 26 & $\mathrm{~m}$ & 64 & glioblastoma & IV & right temporal \\
\hline 27 & $f$ & 59 & glioblastoma & IV & left insular \\
\hline 28 & $\mathrm{~m}$ & 52 & glioblastoma & IV & right frontal \\
\hline 29 & f & 68 & glioblastoma & IV & right temporo-occipital \\
\hline 30 & $\mathrm{~m}$ & 65 & glioblastoma & IV & right temporal \\
\hline 31 & $\mathrm{~m}$ & 59 & glioblastoma & IV & right frontal \\
\hline 32 & $f$ & 76 & glioblastoma & IV & right temporal \\
\hline 33 & $\mathrm{~m}$ & 76 & glioblastoma & IV & left temporo-parietal \\
\hline 34 & $f$ & 59 & glioblastoma & IV & left temporal \\
\hline 35 & $\mathrm{~m}$ & 66 & glioblastoma & IV & left parieto-occipital \\
\hline 36 & $\mathrm{~m}$ & 47 & glioblastoma & IV & left temporal \\
\hline 37 & $\mathrm{~m}$ & 47 & glioblastoma & IV & right frontal \\
\hline 38 & $f$ & 60 & glioblastoma & IV & right parietal \\
\hline 39 & $\mathrm{~m}$ & 62 & glioblastoma & IV & left frontal \\
\hline 40 & $\mathrm{~m}$ & 61 & glioblastoma & IV & left fronto-parietal \\
\hline 41 & $\mathrm{~m}$ & 57 & glioblastoma & IV & left frontal \\
\hline \multicolumn{6}{|c|}{ meningiomas } \\
\hline 42 & $\mathrm{~m}$ & 41 & meningioma & I & right parietal convexity \\
\hline 43 & $f$ & 37 & meningioma & I & right temporo-basal \\
\hline 44 & $f$ & 38 & anaplastic meningioma & III & $\begin{array}{l}\text { bilateral cerebral con- } \\
\text { vexity }\end{array}$ \\
\hline 45 & $f$ & 51 & meningioma & 1 & left frontal convexity \\
\hline 46 & $\mathrm{~m}$ & 49 & anaplastic meningioma & III & right pterional \\
\hline 47 & $\mathrm{~m}$ & 44 & atypical meningioma & II & right fronto-temporal \\
\hline \multicolumn{6}{|c|}{ other CNS primary tumors } \\
\hline 48 & $f$ & 25 & ependymoma & 1 & right temporal \\
\hline 49 & $\mathrm{~m}$ & 24 & cavernoma & I & right occipital \\
\hline 50 & $f$ & 25 & cavernoma & I & right temporal \\
\hline \multicolumn{6}{|c|}{ secondary brain lesions } \\
\hline 51 & $f$ & 60 & lung metastasis & - & right frontal \\
\hline 52 & $f$ & 58 & lung metastasis & - & right temporo-occipital \\
\hline 53 & $\mathrm{~m}$ & 58 & lung metastasis & - & left frontal \\
\hline 54 & $\mathrm{~m}$ & 61 & lung metastasis & - & right frontal \\
\hline 55 & $\mathrm{~m}$ & 52 & colon metastasis & - & right frontal \\
\hline 56 & $\mathrm{~m}$ & 56 & colon metastasis & - & left parieto-occipital \\
\hline 57 & $\mathrm{~m}$ & 64 & kidney metastasis & - & right frontal \\
\hline 58 & $f$ & 73 & breast metastasis & - & right frontal \\
\hline
\end{tabular}

Table 1 Study population features. 


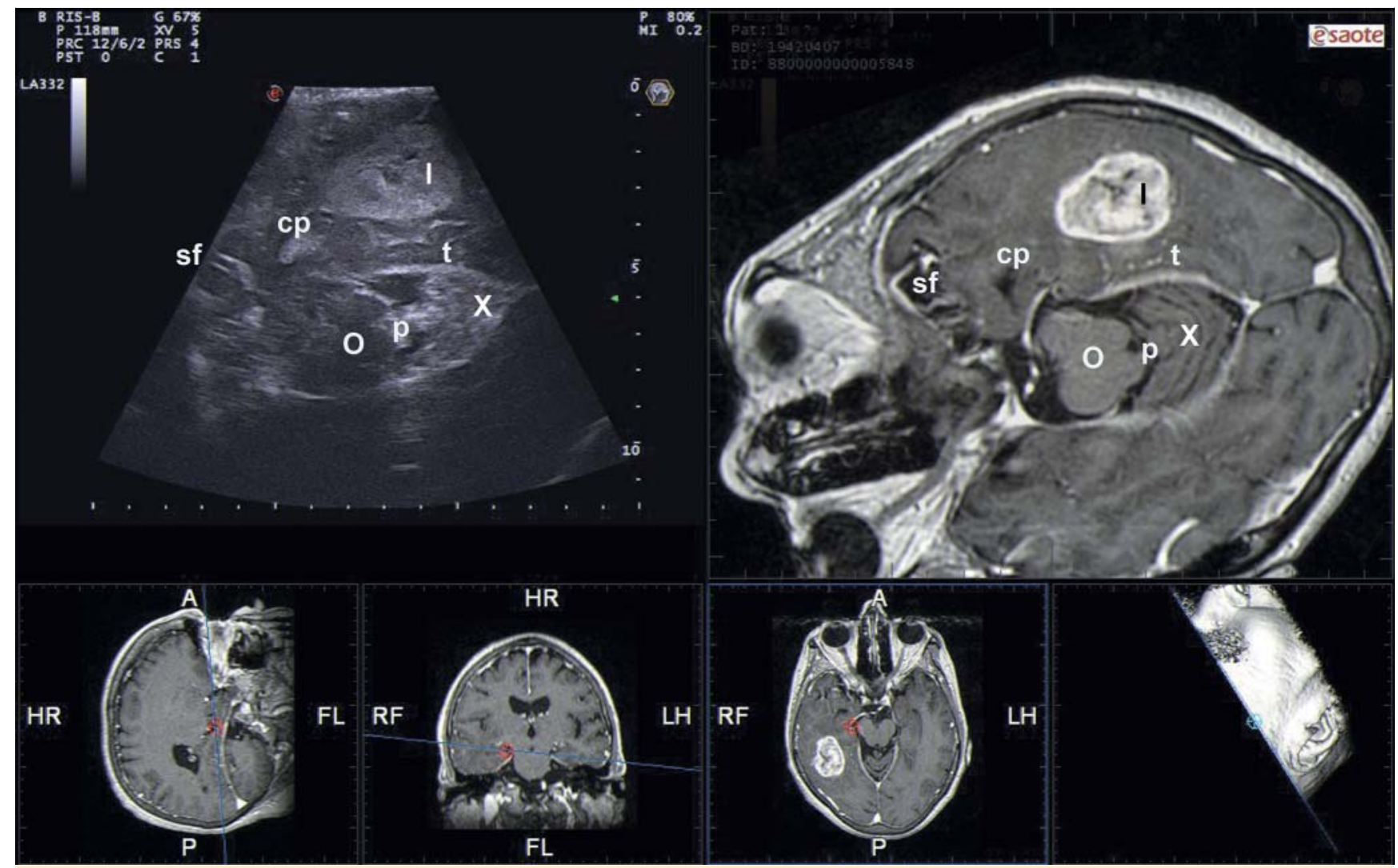

Fig. 11 Example of intraoperative identification of internal anatomical landmarks in a case of right temporal posterior mesial basal glioblastoma (I): right tentorial free edge $(t)$, cerebellar vermis $(x)$, temporal horn choroid plexus (cp), mesencephalon (o), pineal gland (p), sylvian fissure (sf).

Abb.11 Beispiel für die intraoperative Identifikation interner anatomischer Landmarken bei einem Fall mit rechtstemporalem posterior mesial-basalem Glioblastom (I): rechte tentoriale freie Ecke (t), Kleinhirnwurm (x), Plexus choroideus des Temporalhorns, Mesencephalon (o), Zirbeldrüse (p), lateraler Sulcus (sf).

capitalize then on the MRI image clarity rather than to see all brain details on an optimal setup of a US image

Motivated by the success of fusion imaging and willing to bypass the known drawbacks of conventional neuronavigation, we have adopted the technology with an approach that is adapted to brain surgery. Our system makes it possible to compare the US image and corresponding MRI image in two ways. One approach is to split the screen into two side-by-side windows, one for ioUS and one for the preoperative MRI. The other approach consists of superimposing the MRI image over the US image with the possibility to adjust the transparency of the two images in order to see only MRI, only ioUS, or a combination of the two. In general MRI provides an overview, while US is employed only in the region of interest. This feature allows the surgeon to understand the situation in toto. Embedding the US image within the corresponding co-planar MRI slice facilitates understanding of the orientation and location of the US field, while ultrasound simultaneously displays dynamic highly detailed images of the region of interest. Moreover, thanks to the continuous comparison of US to the standard MRI modality, an inexperienced US user can visually recognize how a certain structure is depicted in the US images. We believe that this could enormously shorten the learning curve while improving the quality of surgery and the patient outcome. We fully endorse the point of view of Moiyadi A et al. that residents and neurosurgical trainees should be exposed to ioUS early during their training in order to get comfortable with image interpretation and to reduce the steep learning curve $[27,28]$ and we believe that fusion imaging could be important in this sense.
Our typical workflow consists of a first phase of "conventional navigation", based on preoperative MRI images only, and a second phase, based on merged images from intraoperative US and preoperative MRI and enhanced by brain shift correction. Thus our US-MRI fusion imaging neuronavigation approach can be divided into four steps:

1. Plan the craniotomy and understand the anatomy and relations of the lesion, as with conventional neuronavigation

2. After dura opening, correct brain shift employing now internal brain landmarks

3. During the whole process, provide MRI "reference images" parallel to the US scan in real time

4. Once these are clearly adjusted, one can (if necessary) safely rely on US images only for the rest of the operation.

There are a few technical issues that we would like to point out: In the first step, we use the system as any conventional neuro-navigator. In regard to initial registration employing external points, we (and others in the past) have observed a higher level of precision when using (external) anatomical landmarks such as eyes, ears and nose, compared to the skin-adhesive fiducial marker registration approach, obviously because markers may move with the skin. Therefore, we did not use fiducial markers for initial registration, and thus increased accuracy and patient comfort. In all 58 cases performed with the Virtual Navigation technique, we observed a great accuracy of correlation between US and preoperative MRI, since we were able to identify and easily recognize fixed anatomical structures, and also the margins 
of the lesions, as confirmed with postoperative MRI and the histological analysis.

In the second step after dura opening during surgery, significant brain shift occurred in 42 of the 58 patients, making the initial registration inadequate. At this stage of the operation, we postulate that merely the location of the brain changes (shifts and possibly rotates). However, the overall brain shape remains unchanged. Therefore, we adopted a fast and intuitive brain shift correction method based on rigid affine transformation employing internal anatomic landmarks to be identified by tracked US. In these cases we use the fine-tuning option, a methodology originating from interventional radiologists and used so far for US imaging of the liver, kidney, etc. rather than neuronavigation that allows intuitive correction of alignment errors and recalibration of preoperative MRI relying on intraoperative US imaging. This is in fact a manual recalibration operation based on internal anatomical landmarks and can be achieved in two ways, depending on whether the error occurs "on plane" (two dimensions) or "in space" (three dimensions). In the first case the plane of insonation is aligned to MRI and, thus, the misalignment is observed in the vertical and horizontal directions. In this case of "on-plane" misalignment, the user holds the probe more or less parallel to one of the principal MRI planes (axial, coronal or sagittal), finds a plane with clear landmarks visible on both imaging modalities, freezes both US and MRI imaging and then shifts one of the images over the other until the misalignment disappears (video 2). This is a fast and easy method and was used successfully in 36 of the 42 cases. In the second case of "in space" shifting where the third dimension is also lost as was the case in 6 of our 42 patients, it is necessary to freeze one of the two imaging modalities at a location showing clear landmarks and to scan the patient with the other modality until a plane showing the same orientation and landmarks is found. We are aware that the aim of fine-tuning is to adjust the highest possible accuracy in the area of interest. Therefore, if the lesion is at a depth of $2 \mathrm{~cm}$ from the probe, the highest registration accuracy is needed at $2 \mathrm{~cm}$ and inaccuracy at a depth of $8 \mathrm{~cm}$, for example, is less relevant. In conclusion, we optimized fine-tuning at the location of the tumor rather than optimizing registration error globally, postulating thereby a local-rigid deformation. From our liver and kidney experience, we know that this is a valid hypothesis.

Regarding the third step, we observed that fusion imaging can shorten the learning curve of the US anatomy, leading, with accumulated experience, to use of only US imaging during surgery.

Lastly, regarding the fourth step, after partial or total tumor resection, we are also aware that the two imaging modalities (preoperative MRI and current US) no longer show the same anatomical situation. Therefore, the above-described fine-tuning approach postulating local-affine rigid deformations is not valid and cannot be applied anymore. One possible future solution to this is the development of non-elastic deformations, a step already under development and to be published at a later stage. With the current version of the VN system in our clinical routine, we continue using navigation to the end of the operation, but the further we progress with the surgery, the more we mainly rely on US imaging and use MRI as a reference for orientation and interpretation of the sonographic images in a wider anatomic context. As already pointed out on step three, we see a great benefit in correlating MRI and US images, especially for non-expert sonographers. Furthermore, this is of particular importance when performing surgery close to eloquent brain areas, because US imaging is not able to display and show functional areas and structures. It is in fact important to integrate US with advanced MRI imaging ( $\bullet$ Fig. 11) such as functional MRI (fMRI) and diffusion tensor imaging (DTI) [11]. Before tumor removal, fusion imaging allows identification of functional structures and provides orientation for the surgeon. During tumor removal, after eventual shift has occurred, the continuous updating between the two modalities offers more precise knowledge of the location of functional areas, thus possibly avoiding damage. US provides the anatomical real-time situation while MRI provides a panoramic view and functional information.

To conclude with some critical remarks, the fine-tuning process goes against the current rule of neuronavigation using MRI as a fixed, or leading, imaging modality. This is in fact a manual recalibration operation that relies in our case fundamentally on another imaging modality (US) that has to be mastered by the operator and is based on operator skill and judgment but offers the paramount benefit of "actual" images and intuitive correction of brain shift (and in the future also brain deformation).

There are also a few technical limitations to consider. The size of the tip of the currently used US probe is $1 \mathrm{~cm} . \times 3.5 \mathrm{~cm}$ and needs a relatively wide craniotomy to achieve a good trans-parenchymal window for obtaining clear images. Furthermore, it is difficult to visualize the parenchyma in the case of diffuse bleeding or excessive use of hemostatic material that is highly hyperechoic [29].

\section{Conclusion}

Intraoperative US imaging enhancing conventional neuronavigation has proven to be reliable, accurate and easy to use, permitting continuous real-time feedback. Moreover it is fast, relatively economic and is readily repeatable without interrupting surgery. It is particularly useful when matched with preoperative MRI or CT because Virtual Navigator provides an optimal continuous check of correct insonation by US. We found this to be a paramount benefit because of the lack of US training in the neurosurgical community.

The described procedure, tested on 58 subjects, showed the feasibility of applying our approach for the visualization of intracranial lesions with US, for the compensation of brain shift and the measurement and correction of the extent of resection. The system might be implemented using other US techniques such as CEUS to evaluate real-time tissue perfusion ( $\bullet$ Fig. 10) or adding advanced MRI such as functional MRI (fMRI) and diffusion tensor imaging (DTI) (• Fig. 9).

We think that intraoperative US, especially when coupled with other imaging modalities, should no longer be considered as a secondary alternative to NN, iMRI or iCT. Instead it should be taken into account as a really valuable tool in guiding the surgeon's hands in brain lesion removal, providing real-time feedback and allowing the operator to modify the surgical strategy based on the real intraoperative situation, despite what is depicted by preoperative imaging.

We believe that the main application of this technique is definitely for intra-parenchymal tumor removal, because ioUS can be of help in identifying the lesion and residual mass with great sensitivity [30,31], but we should not underestimate its use for other lesions such as skull base tumors, abscesses, cysts, hematomas and aneurysms. 


\section{Acknowledgments}

$\nabla$

The authors would like to thank Mrs. Caroline King, DipArch, for her kind advice in revising the manuscript. The research leading to these results has received funding from the European Union Seventh Framework Programme FP7/2007-2013 under grant agreement n. 602923

\section{References}

1 Orringer DA, Golby A, Jolesz F. Neuronavigation in the surgical management of brain tumors: current and future trends. Expert Rev Med Devices 2012; 9: $491-500$

2 Dorward NL, Alberti O, Velani B et al. Postimaging brain distortion: magnitude, correlates, and impact on neuronavigation. J Neurosurg 1998; 88: 656-662

3 Nimsky C, Ganslandt O, Cerny S et al. Quantification of, visualization of, and compensation for brain shift using intraoperative magnetic resonance imaging. Neurosurgery 2000; 47: 1070-1090

4 Stieglitz LH, Fichtner J, Andres R et al. The silent loss of neuronavigation accuracy: a systematic retrospective analysis of factors influencing the mismatch of frameless stereotactic systems in cranial neurosurgery. Neurosurgery 2013; 72: $796-807$

5 Black PM, Moriarty T, Alexander EIII et al. Development and implementation of intraoperative magnetic resonance imaging and its neurosurgical applications. Neurosurgery 1997; 41: 831 -845

6 Hammoud MA, Ligon BL, ElSouki $R$ et al. Use of intraoperative ultrasound for localizing tumors and determining the extent of resection: a comparative study with magnetic resonance imaging. J Neurosurg 1996; 84: 737-741

7 Unsgaard G, Gronningsaeter A, Ommedal S et al. Brain operations guided by real-time two-dimensional ultrasound: new possibilities as a result of improved image quality. Neurosurgery 2002; 51: $402-412$

8 Gerganov VM, Samii A, Akbarian A et al. Reliability of intraoperative high-resolution 2D ultrasound as an alternative to high-field strength MR imaging or tumor resection control: a prospective comparative study. J Neurosurg 2009; 111: 512-519

9 Pasto ME, Rifkin MD. Intraoperative ultrasound examination of the brain: possible pitfalls in diagnosis and biopsy guidance. J Ultrasound Med 1984; 3: 245-249

10 Lindner D, Trantakis C, Renner C et al. Application of intraoperative 3D ultrasound during navigated tumor resection. Minim Invasive Neurosurg 2006; 49: 197-202

11 Rasmussen IA Jr, Lindseth F, Rygh OM et al. Functional neuronavigation combined with intra-operative 3D ultrasound: initial experiences during surgical resections close to eloquent brain areas and future directions in automatic brain shift compensation of preoperative data. Acta Neurochir (Wien) 2007; 149: 365-378

12 Jung TY, Jung S, Kim IY et al. Application of neuronavigation system to brain tumor surgery with clinical experience of 420 cases. Minim Invasive Neurosurg 2006; 49: 210-215

13 Montali G, Solbiati L, Croce F et al. Fine-needle aspiration biopsy of liver focal lesions ultrasonically guided with a real-time probe. Report on 126 cases. Br J Radiol 1982; 55: 717-723

14 De Beni S, Macciò M, Bertora F. Multimodality Navigation Tool 'Navigator'. IMEKO, IEEE, SICE 2nd International Symposium on Measurement, Analysis and Modeling of Human Functions, 1st Mediterranean Conference on Measurement, June 14-16 Genova, Italy: 2004
15 Park HJ, Lee MW, Lee MH et al. Fusion imaging-guided percutaneous biopsy of focal hepatic lesions with poor conspicuity on conventional sonography. J Ultrasound Med 2013; 32: 1557-1564

16 Crocetti L, Lencioni R, Debeni S et al. Targeting liver lesions for radiofrequency ablation: an experimental feasibility study using a CT-US fusion imaging system. Invest Radiol 2008; 43: 33-39

17 Jung EM, Schreyer AG, Schacherer D et al. New real-time image fusion technique for characterization of tumor vascularisation and tumor perfusion of liver tumors with contrast-enhanced ultrasound, spiral CT or MRI: first results. Clin Hemorheol Microcirc 2009; 43: 57-69

18 Nakai M, Sato M, Sahara $S$ et al. Radiofrequency ablation assisted by real-time virtual sonography and CT for hepatocellular carcinoma undetectable by conventional sonography. Cardiovasc Interv Radiol 2009; 32: $62-69$

19 Giesel FL, Mehndiratta A, Locklin J et al. Image fusion using CT, MRI and PET for treatment, planning, navigation and follow up in percutaneous RFA. Exp Oncol 2009; 31: $106-114$

20 Ross CJ, Rennert J, Schacherer $D$ et al. Image fusion with volume navigation of contrast enhanced ultrasound (CEUS) with computed tomography (CT) or magnetic resonance imaging (MRI) for post-interventional follow-up after transcatheter arterial chemoembolization (TACE) of hepatocellular carcinomas (HCC): preliminary results. Clin Hemorheol Microcirc 2010; 46: 101 - 115

21 Bucholz RD, Yeh DD, Trobaugh J et al. The correction of stereotactic inaccuracy caused by brain shift using an intraoperative ultrasound device. CVRMed-MRCASL 1997: 459-466

22 Comeau RM, Sadikot AF, Fenster A et al. Intraoperative ultrasound for guidance and tissue shift correction in image-guided neurosurgery. Med Phys 2000; 27: 787-800

23 Schlaier JR, Warnat J, Dorenbeck $U$ et al. Image fusion of MR images and real-time ultrasonography: evaluation of fusion accuracy combining two commercial instruments, a neuronavigation system and a ultrasound system. Acta Neurochir (Wien) 2004; 146: 271 - 276

24 Gonzalez J, Sosa-Cabrera D, Ortega M et al. Ultrasound Based Intraoperative Brain Shift Correction. IEEE Ultrasonics Symposium. Proceedings 2007: 1571

25 Prada F, Perin A, Martegani A et al. Intraoperative contrast-enhanced ultrasound for brain tumor surgery. Neurosurgery 2014; 74: 542 552. DOI: $10.1227 /$ NEU.0000000000000301.

26 Prada F, Mattei L, Del Bene M et al. Intraoperative cerebral glioma characterization with Contrast Enhanced Ultra-Sound. Biomed Res Int 2014; 2014: 484261. DOI: 10.1155/2014/484261

27 Moiyadi AV. Objective assessment of intraoperative ultrasound in brain tumors. Acta Neurochir 2014; 156: $703-704$

28 Moiyadi A, Shetty P. Objective assessment of utility of intraoperative ultrasound in resection of central nervous system tumors: A cost-effective tool for intraoperative navigation in neurosurgery. J Neurosci Rural Pract 2011; 2: 4-11. DOI: 10.4103/0976-3147.80077

29 Selbekk T, Jakola AS, Solheim $O$ et al. Ultrasound imaging in neurosurgery: approaches to minimize surgically induced image artefacts for improved resection control. Acta Neurochir 2013; 155: 973-980

30 Le Roux PD, Berger MS, Wang K et al. Low grade gliomas: comparison of intraoperative ultrasound characteristics with preoperative imaging studies. J Neurooncol 1992; 13: 189-198

31 Woydt M, Krone A, Becker G et al. Correlation of intra-operative ultrasound with histopathologic findings after tumour resection in supratentorial gliomas - A method to improve gross total tumour resection. Acta Neurochir (Wien) 1996; 138 (12): 1391 - 1398 